\title{
Anti-obesity Effects of the Administration of Tournefortia paniculata Cham Extract on Wistar Rats Subjected to a Hypercaloric Diet
}

\author{
Anderson Assaid Simão ${ }^{1}$, Vinicius de Oliveira $\operatorname{Ramos}^{1}$, Angelita Duarte Corrêa ${ }^{1 *}$, \\ Raimundo Vicente de Sousa ${ }^{2}$ and Silvana Marcussi ${ }^{1}$ \\ ${ }^{I}$ Departamento de Química; Universidade Federal de Lavras; Lavras - MG - Brasil. ${ }^{2}$ Departamento de Medicina \\ Veterinária; Universidade Federal de Lavras; Lavras - MG-Brasil
}

\begin{abstract}
The aim of this study was to evaluate the therapeutic and toxicologic effects of the administration of the powered vegetable extract and aqueous extract of Tournefortia paniculata leaves on Wistar rats, subjected to a hypercaloric diet for 42 days. The rats were divided into five groups and were given the following treatments by gavage: T0 (control) - $1.0 \mathrm{~mL}$ water day ${ }^{-1} ; \mathrm{Tl}$ - aqueous extract containing $14 \mathrm{mg}$ phenolic compounds $\mathrm{kg}^{-1} \mathrm{rat} \mathrm{day}^{-1} ; \mathrm{T2}-14$ $\mathrm{mg}$ quercetin $\mathrm{kg}^{-1}$ rat day $\mathrm{y}^{-1} \mathrm{T3}-50 \mathrm{mg}$ powered vegetable extract from T. paniculata leaves $(P V E) \mathrm{kg}^{-1} \mathrm{rat} \mathrm{day}^{-1}$ and T4 - $100 \mathrm{mg} \mathrm{PVE} \mathrm{kg}^{-1}$ rat day-1. The treatments did not significantly alter the weight, but were effective in reducing liver fat, glucose and serum triglycerides. The treatment $T 1$ reduced food consumption and lipid peroxidation. None of the treatments showed genotoxic potential. Results showed that T. paniculata leaves possessed an anti-obesity potential. However, a more detailed study of the medicinal potential and characterization of phytochemicals in this plant would be still necessary for a better understanding of its mechanisms of action, enabling future applications in the treatment of this pathology or for various therapeutic purposes.
\end{abstract}

Key words: Obesity, medicinal plants, pharmacology, antioxidants, genotoxicity

\section{INTRODUCTION}

Due to the consequences caused by the obesity and its rapid spread throughout the world, it has been considered a global epidemic, with over one billion overweight adults, from which 400 million are clinically obese, from the both developed and developing countries, including Brazil (Tucci et al. 2010). Its incidence is independent of socioeconomic factors and age, and its consequences range from the development of debilitating diseases to death, directly affecting the quality of life of individuals.

Among the options available for the treatment of obesity, the most used ones are balanced diets, regular physical exercises and drug treatments, ranging from lipase inhibitors to anorectics. However, due to side effects and the high cost of drugs traditionally used in the treatment of this disease, the potential of natural products for the treatment of obesity is being widely explored, and they may be a viable alternative for the future development of effective and safe anti-obesity drugs (Park et al. 2005; Mayer et al. 2009). Mixtures of phytochemicals or isolated molecules identified from the plants represent an excellent opportunity for the development of such therapeutics (Birari and Bhutani 2007).

Tournefortia paniculata Cham., traditionally known as marmelinho, is a shrub belonging to the

*Author for correspondence: angelita@dqi.ufla.br 
family Boraginaceae. Its origin is attributed to the Mediterranean regions and the United States, occurring widely in the tropics and subtropics (Moraes and Sousa 2007). In Brazil, its leaves are used in folk medicine as a diuretic, antiinflammatory in the urinary tract and in the cases of nephrolithiasis (Bertolucci 2000). There are reports that the aqueous extract of $T$. paniculata leaves can act in the treatment of obesity, because of its high inhibitory activity in vitro on the enzymes $\alpha$-amylase and $\alpha$-glucosidase (Simão et al. 2012). The in vitro antioxidant potential has also been observed in the aqueous extract of the leaves (Simão et al. 2013), if demonstrated in vivo, could be an important tool to aid in the treatment of obesity, since many diseases directly related to obesity, such as diabetes, cardiovascular diseases, hypertension, among others, may be caused or exacerbated by free radicals (Villareal et al. 2005). Simão et al. (2013) found high contents of phenolic compounds in $T$. paniculata leaves (36.19 g/100 g dry matter); such substances could provide several benefits for the treatment of obesity and other diseases, since they have an inhibitory effect on digestive enzymes, as well as antioxidant and antiglycemic properties. Apparently phenolic compounds present in it could be the substances responsible for the possible anti-obesity effects of these leaves.

In this study, based on in vitro results, the potential therapeutic and toxicological effects of the administration of the powered vegetable extract (rich in phenolic compounds) and aqueous extract of $T$. paniculata leaves were evaluated on the metabolism of Wistar rats subjected to a hypercaloric diet in order to determine the possible anti-obesity properties, as well as safe and effective doses for the development of therapeutic formulations from this plant.

\section{MATERIAL AND METHODS}

\section{Obtain the powered vegetable extract and the aqueous extract of leaves Tournefortia paniculata}

Fresh leaves of $T$. paniculata Cham (marmelinho) were obtained from the municipal market of Belo Horizonte, Minas Gerais, Brazil in January 2011. Its sample was deposited in the ESAL Herbarium of the Biology Department of the Universidade Federal de Lavras, under registration No. 15818. The leaves were washed under running, then with the distilled water and were placed in forced-air oven for drying at $\pm 35^{\circ} \mathrm{C}$ for $48 \mathrm{~h}$. After drying, the leaves were ground in a Wiley type mill and were then passed through an 80 -mesh sieve $(0.2$ $\mathrm{mm})$ to obtain the powered vegetable extract from T. paniculata (PVE). The PVE was added to water in the ratio $1: 25(\mathrm{w} / \mathrm{v})$, kept under agitation for 60 min at room temperature and then centrifuged at $10,000 \times \mathrm{g}$ for $10 \mathrm{~min}$ and the supernatant was collected and used for the analyzes.

\section{Bioassay \\ Animals and experimental conditions}

The experiment was developed in accordance with the ethical principles in animal experimentation, according to the Law 11.794 of October 2008, and the project was approved by the Ethics Committee on Animal Use of Universidade Federal de Lavras (UFLA - Protocol 014/11). The experiment was conducted over 10 weeks, using 30 male Wistar rats (Rattus norvegicus), with initial body weight of approximately $243.15 \mathrm{~g}$. The animals were kept in individual cages at $21^{\circ} \mathrm{C}$, light/dark cycle of $12 \mathrm{~h}$, with access to distilled water ad libitum. During the first four weeks, the rats were given a hypercaloric diet containing $46 \%$ commercial food (Biobase Bio-tec Ratos e Camundongos), 46\% condensed milk and $8 \%$ corn oil (Levin et al. 1986). Diets $(1.0 \mathrm{~kg})$ were prepared weekly and stored in a freezer at $-24^{\circ} \mathrm{C}$.

At the end of four weeks consuming the hypercaloric diet, the animals were weighed, and were divided into five groups of six animals each. They were given the hypercaloric diet and the following treatments for six weeks: T0 (control) $1.0 \mathrm{~mL}$ water/day; $\mathrm{T} 1$ - aqueous extract containing $14 \mathrm{mg}$ phenolic compounds/kg rat/day; T2 (positive antioxidant control) - $14 \mathrm{mg}$ quercetina/kg rat/day; $\mathrm{T} 3$ - $50 \mathrm{mg}$ powered vegetable extract from $T$. paniculata leaves (PVE)/kg rat/day and T4 - $100 \mathrm{mg} \mathrm{PVE/kg} \mathrm{rat/day.}$ Each treatment was administered daily, diluted with water, and the administration was performed by gavage, using sterilized stainless steel cannula and syringe $1.0 \mathrm{~mL}$ per animal same time by the same individual.

For the calculation of the dose for the administration of the aqueous extract and quercetin, the maximum dose of phenolics suggested for the humans was considered, i.e., $1,000 \mathrm{mg} /$ day (Scalbert et al. 2005), as well as the average weight of an adult human $(70 \mathrm{~kg})$. For quercetin and PVE, aqueous solutions were 
prepared at the concentrations of 20 and 40 $\mathrm{mg} / \mathrm{mL}$, respectively. For the administration of the PVE at 50 and $100 \mathrm{mg}$, its maximum solubility in water was taken into account.

The volume administered in each treatment was calculated according to the weight of each rat. Thus, a solution volume corresponding to the dose calculated according to the body weight measured on the day was administered to each animal by gavage. The same was done for the control group, to which only water was administered.

\section{Determination of phenolic compounds}

The supernatant obtained in the preparation of the aqueous extract was subjected to the determination of phenolic compounds according to the methodology proposed by the AOAC (2005). For the quantification of these phenolic compounds, $0.05 \mathrm{~mL}$ of the aqueous extract were transferred to a test tube, as well as $3.45 \mathrm{~mL}$ of distilled water, $0.25 \mathrm{~mL}$ of the Folin-Denis reagent, $0.5 \mathrm{~mL}$ of saturated sodium carbonate solution and $0.75 \mathrm{~mL}$ of water, forming a mixture of blue color. After 30 min, the absorbance reading was performed at 760 $\mathrm{nm}$ using a UV-VIS spectrophotometer (Quimis).

The calibration curve was prepared from the absorbance measurements of the standard tannic acid solution $(100 \mathrm{mg} / 1000 \mathrm{~mL})$ (Sigma-Aldrich) in $0.05 ; 0.1 ; 0.2 ; 0.3 ; 0.4 ; 0.5 ; 0.6$ and $0.7-\mathrm{mL}$ aliquots in the test tubes. To these volumes, distilled water was added in decreasing amounts: $3.45 ; 3.4 ; 3.3 ; 3.2 ; 3.1 ; 3.0 ; 2.9$ and $2.8 \mathrm{~mL}$, respectively, $0.25 \mathrm{~mL}$ of the Folin-Denis solution, $0.5 \mathrm{~mL}$ of saturated sodium carbonate solution, and, at the end, $0.75 \mathrm{~mL}$ of water were added. After $30 \mathrm{~min}$, spectrophotometer readings were taken at $760 \mathrm{~nm}$.

\section{Body weight and daily food consumption}

Body weight and food consumption were recorded daily for the evaluation of the parameters weight gain and food consumption and food consumption was calculated by the difference between the offered diet and the leftovers.

\section{End of the bioassay}

At the end of the experiment, the rats were anaesthetized with thiopental sodium $(1.0 \mathrm{~g}$ of sterile powder dissolved in $40 \mathrm{~mL}$ of $0.9 \%$ saline solution) intraperitoneally at a dose of $40 \mathrm{mg} / \mathrm{kg}$. After the collection of 2.0 to $4.0 \mathrm{~mL}$ of blood by cardiac puncture, which caused death by exsanguination, a $15-\mu \mathrm{L}$ aliquot was separated for the evaluation of genotoxicity (comet assay) and the remainder of the blood was centrifuged at $2,500 \mathrm{x} \mathrm{g}$ for $10 \mathrm{~min}$ for the serum, which was kept under refrigeration. After euthanasia, a necropsy was also performed with the removal of internal organs (heart, liver, kidneys and pancreas) as well as liver weighing and preparation of histological slides. The liver was divided into three parts: one for the qualitative analysis of the histology, one for the determination of lipid peroxidation, and one for the determination of ether extract. After the removal of the organs, the head, legs, tail and skin were removed, followed by washing of the carcass with salt solution.

\section{Analysis of liver lipids and carcass}

The carcass, as well as part of the liver, were weighed and lyophilized until constant weight. Then, they were crushed in a mortar and subjected to lipid measurement using the Soxhlet method (AOAC 2005).

\section{Blood laboratory analyses}

The blood serum was used to determine the concentrations of glucose, total cholesterol, HDL cholesterol, triglycerides, activity of the enzymes aspartate aminotransferase (AST), alanine aminotransferase (ALT) and Gamma glutamyl transferase (GGT). Blood constituents were analyzed by the commercial kits (Labtest) and analyzes were carried out with the equipment Automatic Veterinary Biochemical Analyzer Thermoplate.

\section{Lipid peroxidation}

The lipid peroxidation was determined by the formation of thiobarbituric acid reactive substances (TBARS) according to Winterbourn et al. (1985). The livers of the animals were weighed and homogenized in a Potter tissue homogenizer in an ice bath after the addition of buffered saline in $0.1 \mathrm{~mol} / \mathrm{L}$ sodium phosphate $\mathrm{PBS}, \mathrm{pH}$ 7.4; volume equivalent to four times the fresh weight of the tissue). The homogenate was centrifuged at 3,000 $\mathrm{x} \mathrm{g}$ at $4^{\circ} \mathrm{C}$ for $10 \mathrm{~min}$ and the supernatant, kept in an ice bath, was used in the assays. Five hundred lilliliter aliquots of the supernatant were mixed with $500 \mu \mathrm{L}$ of $25 \%$ hydrochloric acid (v/v), 500 $\mu \mathrm{L}$ of $1 \%$ thiobarbituric acid (w/v, in $0.05 \mathrm{~mol} / \mathrm{L}$ $\mathrm{NaOH})$ and $45 \mu \mathrm{L}$ of $2 \% \mathrm{BHT}(\mathrm{w} / \mathrm{v}$, in ethanol). The mixture was heated in a boiling water bath for $10 \mathrm{~min}$. After cooling in an ice bath, $1.5 \mathrm{~mL}$ of butanol were added and the samples were shaken 
vigorously, centrifuged at $900 \mathrm{x} \mathrm{g}$ for $5 \mathrm{~min}$, and the fraction containing butanol was collected and used for the determination of the absorbance at $532 \mathrm{~nm}$. The TBARS concentration was calculated from the standard curve of malondialdehyde MDA (1,1,3,3 tetraethoxypropane). The results were expressed in the moles MDA/mg fresh sample.

\section{Comet assay}

The comet assay was performed according to the methodology described by Singh et al. (1988), with some modifications. An aliquot $(15 \mu \mathrm{L})$ of each cell suspension containing the treatments was mixed with $100-\mu \mathrm{L}$ low melting point agarose $(0.5 \% \mathrm{w} / \mathrm{v}$ in PBS), applied to a microscope slide previously coated with normal melting point agarose solution (1\% w/v in PBS), overlaid with a coverslip $(24 \times 60 \mathrm{~mm})$ and kept at $\pm 4^{\circ} \mathrm{C}$ for 5 $\mathrm{min}$, until solidification of the agarose. For each treatment/rat, two slides were prepared. Then, the coverslips were removed and slides were immersed in lysis solution $(2.5 \mathrm{~mol} / \mathrm{L} \mathrm{NaCl}, 100$ $\mathrm{mmol} / \mathrm{L}$ EDTA, $10 \mathrm{mmol} / \mathrm{L}$ Tris, $1 \%$ Triton $\mathrm{X}$ $100,10 \%$ DMSO; $\mathrm{pH} 10$ ) at $4^{\circ} \mathrm{C}$ for $24 \mathrm{~h}$.

After the lysis, slides were kept for $25 \mathrm{~min}$ in a freshly prepared electrophoresis solution (1 $\mathrm{mmol} / \mathrm{L}$ EDTA, $300 \mathrm{mmol} / \mathrm{L} \mathrm{NaOH}$; pH 13.0), allowing the loosening of bonds in DNA molecules and the exposure of alkali-labile sites. The electrophoresis was conducted at $25 \mathrm{~V}$ for 35 $\mathrm{min}$. After the electrophoresis, the slides were kept in a neutralization solution $(0.4 \mathrm{~mol} / \mathrm{L}$ Tris; $\mathrm{pH}$ 7.5) for $30 \mathrm{~min}$ and then dried and fixed with $100 \%$ ethanol. All the procedures were performed in the dark.

\section{Staining and analysis}

The slides were stained with $45 \mu \mathrm{L}$ propidium iodide solution $(1.0 \mathrm{mg} / \mathrm{mL})$, overlaid with a coverslip and analyzed in an epifluorescence microscope (Nikon ECLIPSE E400) using a 200x magnification.In order to measure the damage levels in lymphocyte DNA molecules, 100 nucleoids of each slide, two slides per treatment/rat (totaling 200 nucleoids per treatment/rat), were counted and classified by the same evaluator using visual score patterns described by Singh et al. (1988). The cells were classified according to the size of the "tail" and the diameter of the "head" in Class 0: no damage (damage $<5 \%$ ); Class 1: low damage level (5$20 \%)$; Class 2: intermediate damage level (20-
40\%); Class 3: high damage (40-85\%); Class 4: totally damaged (damage> $85 \%$ ). The average frequency of damage was calculated from the sum of the percentages of damage 1,2, 3 and 4 . The arbitrary units $(0-400$; where $0=$ no damage and $400=100 \%$ damage) were calculated by the equation $(1 \mathrm{x}$ number of nucleoids grouped in class 1$)+(2 \times$ number of nucleoids in class 2$)+(3$ $\mathrm{x}$ number of nucleoids in class 3$)+(4 \mathrm{x}$ number of nucleoids in class 4) as described by Collins (2004).

\section{Histopathology}

For the histopathological analyses, slides containing cuts from the heart, liver, kidneys and pancreas of each rat were prepared. They were immersed in $10 \%$ formalin for $24 \mathrm{~h}$ and kept in $70 \%$ alcohol until inclusion in paraffin. Then $4-\mu \mathrm{m}$ cuts were made in a rotary microtome, stained with hematoxylin-eosin, mounted on slides/coverslips and analyzed under light microscopy (100x magnification) for the qualitative analysis.

\section{Statistical analysis}

The experiment was conducted in a completely randomized design. For data on weight gain, the plots were subdivided in a $5 \times 7$ scheme, i.e., five treatments, a seven-week experiment with six replicates. For the data on food consumption, the plots were subdivided in a $5 \times 6$ scheme, with five treatments, a six-week experiment with six replications. For the other analyzes, five treatments with six replicates were used and, when the analysis of variance showed significance, the comparison of means by the Scott-Knott test (P $<0.05)$ was performed using the Sisvar program (Ferreira 2003).

\section{RESULTS AND DISCUSSION}

The content of phenolic compounds in the aqueous extract and powered vegetable extract from $T$. paniculata leaves were 16.25 and $40.62 \mathrm{mg} 100$ $\mathrm{mg}^{-1}$, respectively. Figure 1 shows the body weight of animals subjected to different treatments during the six weeks of the experiment. The average weights of the rats showed no significant differences among the treatments. However, the average weight gain of the animals in the groups T0, T2, T3 and T4 was $10.20,4.57,3.07$ and $7.11 \%$, respectively, while for the $\mathrm{T} 1$ group, a 
weight loss was observed in the animals (5.8\%), although not statistically different.

In another study with the aqueous extract of $T$. paniculata leaves, an in vitro inhibition of the enzymes $\alpha$-amylase and $\alpha$-glucosidase was observed, and this inhibitory effect was one of the possible mechanisms responsible for weight reduction, considering lower carbohydrate absorption (Simão et al. 2012).

Souza et al. (2012) evaluated the anti-obesity effects of the methanol extract of Baccharis trimera leaves, administered to Wistar rats by gavage. They observed a reduction in the weights of the animals and suggested a possible mechanism of action based on the inhibition of lipases and glycosidases, which were inhibited in vitro by the methanol extract of this plant. These results showed that medicinal plants having digestive enzyme inhibitors in their extracts, as was the case of $T$. paniculata, could be useful for limiting the absorption of fat and carbohydrates of the diet, resulting in weight loss.

The average daily food consumption by the animals is shown in Figure 2. The treatment T1 showed a significant effect, reducing food consumption, thus was effective in reducing the appetite, which characterized an anorexigenic action by an unknown mechanism, and this inhibition could be related to the weight loss observed for this treatment (Fig. 1).

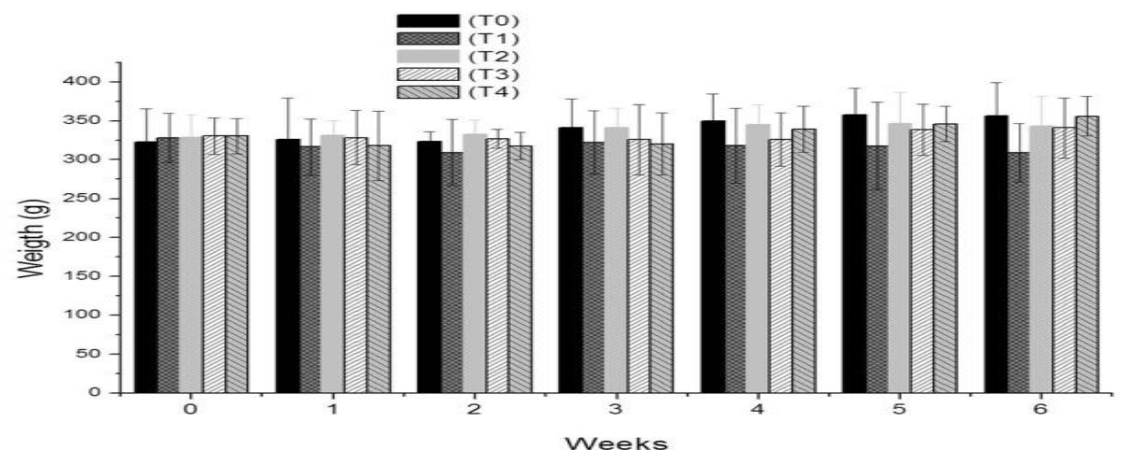

Figure 1 - Body weight of Wistar rats subjected to the treatments: T0 (control) - $1 \mathrm{~mL}$ water/day; T1 aqueous extract containing $14 \mathrm{mg}$ phenolic compounds/kg rat/day; T2 - $14 \mathrm{mg}$ quercetina/kg rat/day; T3 - $50 \mathrm{mg}$ flour from Tournefortia paniculata leaves (FTL)/kg rat/day and T4 - 100 $\mathrm{mg}$ FTL/kg rat/day, for six weeks. Data represent the mean of six replications \pm standard deviation of the average weight for each week of experiment.

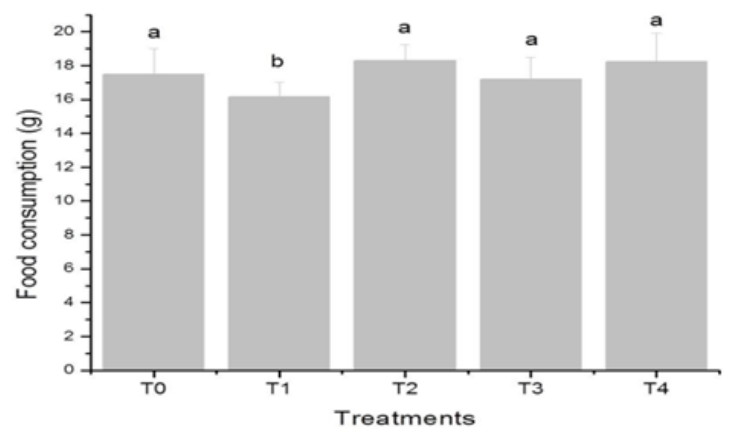

Figure 2 - Food consumption of Wistar rats subjected to the treatments: T0 (control) - $1 \mathrm{~mL}$ water/day; $\mathrm{T} 1$ - aqueous extract containing $14 \mathrm{mg}$ phenolic compounds/kg rat/day; T2 - $14 \mathrm{mg}$ quercetina/kg rat/day; T3 - $50 \mathrm{mg}$ flour from Tournefortia paniculata leaves (FTL) $/ \mathrm{kg}$ rat/day and T4 - $100 \mathrm{mg} \mathrm{FTL/kg} \mathrm{rat/day,} \mathrm{for}$ six weeks. Same letters in columns do not differ by the Scott-Knott test $(\mathrm{P}<0.05)$.

Table 1 shows the average weights of the livers, the liver weight/carcass weight ratio and the levels of body and hepatic fat, with no statistical difference among the treatments for the average weights of the livers, the liver weight/carcass weight ratio and the levels of body fat. The treated groups showed levels of liver fat significantly lower than the group T0 (control), with a reduction of $18.34,22.01,39.32$ and $34.77 \%$ for the groups $\mathrm{T} 1, \mathrm{~T} 2, \mathrm{~T} 3$ and $\mathrm{T} 4$, respectively.

Considering that the liver would be affected by possible antinutritional factors present in $T$. paniculata leaves, damage could reflect on anatomical changes in the treated groups, which did not occur, thus discarding, under the conditions of this experiment, the induction of hypertrophy and hyperplasia.

Table 2 presents the results of some biochemical indicators measured in the blood of the animals under study. For serum glucose, only the treatment T1 was able to significantly reduce the concentration of glucose in relation to the group 
T0 (control), demonstrating a higher hypoglycemic potential of the aqueous extract of $T$. paniculata leaves, compared to other treatments. This reduction could be due to the inhibition of the enzymes $\alpha$-amylase and $\alpha$ glucosidase, reducing the glucose concentration through the lower carbohydrate absorption (Simão et al. 2012), and through the lower food consumption observed for this treatment (Fig. 2).
Some authors have attributed the hypoglycemic effect of plants to the phenolic compounds present in their extracts (Figueroa-Valverde et al. 2009; Urzêda et al. 2013). Thus, these compounds, present in $T$. paniculata leaves, could be responsible for the reduction of the glucose concentration observed in the present study.

Table 1 - Average liver weight, liver weight/carcass weight, body and hepatic fat of Wistar rats subjected to treatments ${ }^{1}$ for six weeks.

\begin{tabular}{lccccc}
\hline Parameter & T0 & T1 & T2 & T3 & T4 \\
\hline Liver weight $(\mathrm{g})$ & $7.71 \pm 1.10^{\mathrm{a}}$ & $7.12 \pm 1.39^{\mathrm{a}}$ & $7.79 \pm 1.01^{\mathrm{a}}$ & $7.95 \pm 1.36^{\mathrm{a}}$ & $8.24 \pm 0.74^{\mathrm{a}}$ \\
Liver weight/total body weight $(\%)$ & $4.49 \pm 0.85^{\mathrm{a}}$ & $4.54 \pm 0.70^{\mathrm{a}}$ & $4.69 \pm 0.27^{\mathrm{a}}$ & $4.82 \pm 0.60^{\mathrm{a}}$ & $4.99 \pm 0.40^{\mathrm{a}}$ \\
Hepatic fat $(\mathrm{g} / 100 \mathrm{~g})$ & $13.63 \pm 0.84^{\mathrm{a}}$ & $11.13 \pm 1.39^{\mathrm{b}}$ & $10.63 \pm 1.05^{\mathrm{b}}$ & $8.27 \pm 0.99^{\mathrm{c}}$ & $8.89 \pm 1.25^{\mathrm{c}}$ \\
Body fat $(\mathrm{g} / 100 \mathrm{~g})$ & $18.92 \pm 1.93^{\mathrm{a}}$ & $17.24 \pm 1.61^{\mathrm{a}}$ & $17.76 \pm 2.74^{\mathrm{a}}$ & $17.01 \pm 1.98^{\mathrm{a}}$ & $19.35 \pm 1.10^{\mathrm{a}}$ \\
\hline
\end{tabular}

Data are the mean of six replicates \pm standard deviation. ${ }^{1}$ Treatments: T0 (control) - $1 \mathrm{~mL}$ water/day; T1 - aqueous extract containing 14 $\mathrm{mg}$ phenolic compounds/kg rat/day; T2 - $14 \mathrm{mg}$ quercetina/kg rat/day; T3 - $50 \mathrm{mg}$ powered vegetable extract from T. paniculata leaves (PVE)/kg rat/day and T4 - $100 \mathrm{mg} \mathrm{PVE/kg} \mathrm{rat/day.} \mathrm{Same} \mathrm{letters} \mathrm{in} \mathrm{rows} \mathrm{do} \mathrm{not} \mathrm{differ} \mathrm{by} \mathrm{the} \mathrm{Scott-Knott} \mathrm{test}(\mathrm{P}<0.05)$.

Table 2 - Biochemical parameters of Wistar rats subjected to treatments ${ }^{1}$ for six weeks.

\begin{tabular}{lccccc}
\hline Parameters & T0 & T1 & T2 & T3 & T4 \\
\hline Serum glucose (mg/dL) & $165.16 \pm 17.17^{\mathrm{a}}$ & $140.34 \pm 6.12^{\mathrm{b}}$ & $168.08 \pm 9.34^{\mathrm{a}}$ & $162.31 \pm 8.09^{\mathrm{a}}$ & $177.96 \pm 6.35^{\mathrm{a}}$ \\
Total cholesterol (mg/dL) & $56.16 \pm 4.11^{\mathrm{a}}$ & $55.19 \pm 5.36^{\mathrm{a}}$ & $61.48 \pm 6.67^{\mathrm{a}}$ & $59.63 \pm 4.26^{\mathrm{a}}$ & $58.13 \pm 4.56^{\mathrm{a}}$ \\
HDL cholesterol (mg/dL) & $49.11 \pm 5.36^{\mathrm{a}}$ & $43.77 \pm 2.38^{\mathrm{a}}$ & $47.64 \pm 1.27^{\mathrm{a}}$ & $45.11 \pm 3.91^{\mathrm{a}}$ & $44.33 \pm 4.12^{\mathrm{a}}$ \\
Triglycerides (mg/dL) & $42.51 \pm 1.92^{\mathrm{a}}$ & $29.23 \pm 4.00^{\mathrm{b}}$ & $31.70 \pm 8.73^{\mathrm{b}}$ & $34.40 \pm 3.68^{\mathrm{b}}$ & $32.80 \pm 2.86^{\mathrm{b}}$ \\
$\mathrm{AST}^{2}(\mathrm{U} / \mathrm{L})$ & $77.35 \pm 0.57^{\mathrm{a}}$ & $80.45 \pm 4.06^{\mathrm{a}}$ & $74.35 \pm 5.14^{\mathrm{a}}$ & $71.58 \pm 5.88^{\mathrm{a}}$ & $76.12 \pm 4.82^{\mathrm{a}}$ \\
$\mathrm{ALT}^{3}$ (U/L) & $59.74 \pm 6.32^{\mathrm{b}}$ & $87.25 \pm 16.14^{\mathrm{a}}$ & $63.17 \pm 7.35^{\mathrm{b}}$ & $56.82 \pm 3.15^{\mathrm{b}}$ & $61.49 \pm 4.85^{\mathrm{b}}$ \\
$\mathrm{GGT}^{4}(\mathrm{U} / \mathrm{L})$ & $2.55 \pm 0.00^{\mathrm{a}}$ & $2.48 \pm 0.07^{\mathrm{a}}$ & $2.48 \pm 0.07^{\mathrm{a}}$ & $2.42 \pm 0.19^{\mathrm{a}}$ & $2.50 \pm 0.06^{\mathrm{a}}$ \\
\hline
\end{tabular}

Data are the mean of six replicates \pm standard deviation. ${ }^{\mathrm{I}}$ Treatments: $\mathrm{T} 0$ (control) - $1 \mathrm{~mL}$ water/day; $\mathrm{T} 1$ - aqueous extract containing 14 $\mathrm{mg}$ phenolic compounds/kg rat/day; T2 - $14 \mathrm{mg}$ quercetina/kg rat/day; T3 - $50 \mathrm{mg}$ powered vegetable extract from $T$. paniculata leaves (PVE)/kg rat/day and T4 - $100 \mathrm{mg}$ PVE/kg rat/day, for six weeks. ${ }^{2}$ AST: aspartate aminotransferase. ${ }^{3}$ ALT: alanine aminotransferase. ${ }^{4}$ GGT: Gamma glutamyl transferase. Same letters in rows do not differ by the Scott-Knott test $(\mathrm{P}<0.05)$.

The results showed that there was no statistical difference among the groups, regarding serum concentration of total cholesterol and HDL cholesterol. The treated groups did not differ statistically and triglyceride concentrations were significantly lower than group T0 (control), with a reduction of $31.24,25.43,19.08$ and $22.85 \%$ in the concentration for the groups T1, T2, T3, and T4, respectively.

Table 2 showed that the activities of AST and GGT were statistically equal for all the groups. Regarding ALT, the treatment $\mathrm{T} 1$ showed an activity significantly higher than those recorded in the other groups, with an increase of $46.04 \%$ in the activity, compared to the group T0 (control). Thus, the results of ALT for the treatment T1 suggested that this treatment could cause hepatotoxic effects. The elevation in serum levels of the ALT enzyme activity caused by the treatment $\mathrm{T} 1$ could be probably attributed to a hepatic dysfunction due to a hepatocyte disruption, resulting from the necrosis or changes in the permeability of the cell membrane (Kaneko 1989). Injury or destruction of hepatic cells release transaminases into the bloodstream (Motta 2009), resulting in an increase of their activity.

AST, found primarily in the mitochondria (80\%), in the organs such as heart, liver, kidneys, pancreas and skeletal muscles, was not released as quickly as ALT, which was essentially hepatic and localized in the cytoplasm, thus justifying that statistical changes were recorded only for the concentrations of ALT in relation to the control group in this study. ALT is a more sensitive indicator of acute hepatotoxicity than AST (AlHabori et al. 2002).

The index of oxidative stress, normally caused by the free radicals in the body, was determined by 
lipid peroxidation, which was considered an important marker of oxidative stress, and also one of the main factors involved in cell damage, caused by these radicals (Balu et al. 2005).

The results of lipid peroxidation (Fig. 3) for the treatments $\mathrm{T} 1$ and $\mathrm{T} 2$ were significantly lower than those in group T0 (control), with a reduction of 34.09 and $18.90 \%$, respectively in the MDA concentration. Quercetin (T2) was used as a positive control, because it was a flavonoid with proven antioxidant activity (Duarte-Almeida et al. 2006, Simão et al. 2013). Through in vivo studies, it was possible to observe that quercetin was effective in reducing the TBARS in rat livers (García-Saura et al. 2005, Yamamoto and Oue 2006), justifying its use as a reference substance.

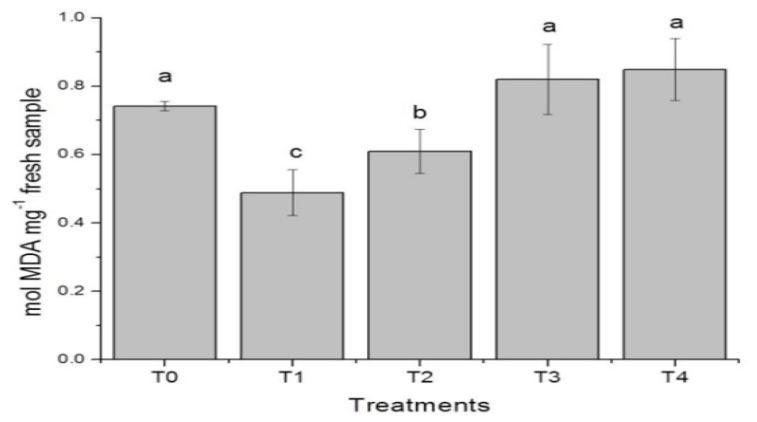

Figure 3 - Production of Thiobarbituric acid reactive substances in the hepatic tissue of Wistar rats subjected to the treatments: T0 (control) - 1 $\mathrm{mL}$ water/day; $\mathrm{T} 1$ - aqueous extract containing $14 \mathrm{mg}$ phenolic compounds $/ \mathrm{kg}$ rat/day; T2 - $14 \mathrm{mg}$ quercetina/kg rat/day; T3 - $50 \mathrm{mg}$ flour from Tournefortia paniculata leaves (FTL)/kg rat/day and T4 - $100 \mathrm{mg}$ FTL/kg rat/day, for six weeks. ${ }^{1} \mathrm{MDA}$ : malondialdehyde. Data are the mean of six replicates \pm standard deviation. Same letters in columns do not differ by the Scott-Knott test $(\mathrm{P}<0.05)$.

The treatment $\mathrm{T} 1$, which had phenolic compounds, could contribute, at least in part, to the antioxidant activity demonstrated in this study, since these compounds have redox properties that allowed them to act as hydrogen donor reducing agents. Yet, the complexation of $\mathrm{Fe}^{+2}$ to phenolic compounds could reduce the availability of this metal involved in the Fenton reaction, in the initiation and propagation of lipid peroxidation (Lima et al. 2006), which could explain the reduction in the MDA concentration by the aqueous extract of $T$. paniculata leaves. For this study, the treatment $\mathrm{T} 1$ showed better results for the antioxidants than the phenolic pattern of quercetin, demonstrating the good antioxidant potential of this plant.

In relation to the treatments $\mathrm{T} 3(50 \mathrm{mg} \mathrm{PVE} / \mathrm{kg}$ rat/day) and T4 (100 mg $\mathrm{PVE} / \mathrm{kg}$ rat/ day), containing 20.31 and $40.62 \mathrm{mg}$ phenolics, respectively, none was able to inhibit the formation of lipid peroxidation products, thus suggesting that the antioxidant substances present in this powered vegetable extract were able to exert antioxidant effects only when they were extracted and concentrated.

It would be worth emphasizing that the treatments used in this study, except for the treatment T2 (quercetin), were not subjected to any purification process for the obtention of active ingredients, i.e.,, there were only the powered vegetable extract and the crude aqueous extract of $T$. paniculata leaves, highlighting its therapeutic potential as an antioxidant and hypoglycemic, even when used without any purification process.

For the results regarding the fragmentation of DNA molecules (Table 3), there was a predominance of nucleoids with no damage (class 0 ), with percentage averages ranging between $43.16 \%$ (T1) and $83.05 \%$ (T0) and with low damage level (class 1), with averages between $16.32 \%$ (T0) and $52.58 \%$ (T1). It was also possible to observe (Table 3) a reduced number of nucleoids with intermediate damage levels (class 2 ), with percentage averages ranging between $0.00 \%$ (T4) and $5.29 \%$ (T1) and absence of nucleoids with high damage levels (class 3 ) and totally damaged DNA (class 4) in all the treatments.

Although the percentages of nucleoids with damage and arbitrary units demonstrated significant differences between the group T0 (control) and the other treatments, these values were related to the damage in class 1 (low damage level) and class 2 (intermediate damage), demonstrating the lack of genotoxicity, considering the six weeks of exposure to the treatments, thus suggesting that, in the composition of the evaluated treatments, there were not molecules capable of causing genotoxic and, consequently, mutagenic effects on the DNA under the experimental conditions used. 
Table 3 - Average nucleoid number per class of comet, frequency of nucleoids with damage and arbitrary units in leukocytes of Wistar rats subjected to treatments for six weeks.

\begin{tabular}{|c|c|c|c|c|c|c|c|}
\hline \multirow[b]{2}{*}{ Treatments $^{2}$} & \multicolumn{5}{|c|}{ Class of comet $(\%)^{T}$} & \multirow{2}{*}{$\begin{array}{l}\text { Frequency of } \\
\text { damage }^{3}(\%)\end{array}$} & \multirow{2}{*}{$\begin{array}{c}\text { Arbitrary } \\
\text { units }^{4}\end{array}$} \\
\hline & 0 & 1 & 2 & 3 & 4 & & \\
\hline T0 & $83.05 \pm 4.28^{\mathrm{a}}$ & $16.32 \pm 3.68^{\mathrm{d}}$ & $0.98 \pm 0.08^{b}$ & $0.00 \pm 0.00$ & $0.00 \pm 0.00$ & $17.30 \pm 3.87^{d}$ & $18.28 \pm 4.20^{\mathrm{d}}$ \\
\hline $\mathrm{T} 1$ & $43.16 \pm 16.53^{\mathrm{d}}$ & $52.58 \pm 11.71^{\mathrm{a}}$ & $5.29 \pm 1.18^{\mathrm{a}}$ & $0.00 \pm 0.00$ & $0.00 \pm 0.00$ & $57.87 \pm 11.86^{\mathrm{a}}$ & $63.16 \pm 13.56^{\mathrm{a}}$ \\
\hline $\mathrm{T} 2$ & $71.30 \pm 5.50^{\mathrm{b}}$ & $28.40 \pm 5.11^{\mathrm{c}}$ & $0.30 \pm 0.03^{c}$ & $0.00 \pm 0.00$ & $0.00 \pm 0.00$ & $28.70 \pm 5.50^{c}$ & $29.00 \pm 5.89^{c}$ \\
\hline $\mathrm{T} 3$ & $59.60 \pm 5.86^{\mathrm{c}}$ & $39.30 \pm 4.66^{\mathrm{b}}$ & $1.13 \pm 0.24^{\mathrm{b}}$ & $0.00 \pm 0.00$ & $0.00 \pm 0.00$ & $40.76 \pm 5.59^{b}$ & $41.56 \pm 5.95^{\mathrm{b}}$ \\
\hline $\mathrm{T} 4$ & $68.18 \pm 9.63^{\mathrm{b}}$ & $31.83 \pm 9.63^{\mathrm{c}}$ & $0.00 \pm 0.00^{\mathrm{b}}$ & $0.00 \pm 0.00$ & $0.00 \pm 0.00$ & $31.83 \pm 9.63^{\mathrm{c}}$ & $31.83 \pm 9.63^{\mathrm{c}}$ \\
\hline
\end{tabular}

${ }^{\mathrm{T}}$ Data represent the mean values obtained in 2 slides, with 100 nucleoids analyzed in each slide, and 4 slides/treatment/rat. 30 rats were used (6 rats/treatment). ${ }^{2}$ Treatments: T0 (control) - $1 \mathrm{~mL}$ water/day; T1 - aqueous extract containing $14 \mathrm{mg}$ phenolic compounds/kg rat/day; T2 - $14 \mathrm{mg}$ quercetina/kg rat/day; T3 - $50 \mathrm{mg}$ powered vegetable extract from $T$. paniculata leaves (PVE)/kg rat/day and T4 $100 \mathrm{mg}$ PVE/kg rat/day. ${ }^{3}$ Frequency of damage: sum of the damage of classes 1 through $4 ;{ }^{4}$ Arbitrary units: $(1 \mathrm{x}$ damage in class 1$)+(2$ $\mathrm{x}$ damage in class 2$)+(3 \mathrm{x}$ damage in class 3$)+(4 \mathrm{x}$ damage in class 4$)$. Same letters in columns do not differ by the Scott-Knott test $(\mathrm{P}$ $<0.05)$.

In Figure 4, images of the histological sections obtained from different organs are shown. No macroscopic changes were observed in the
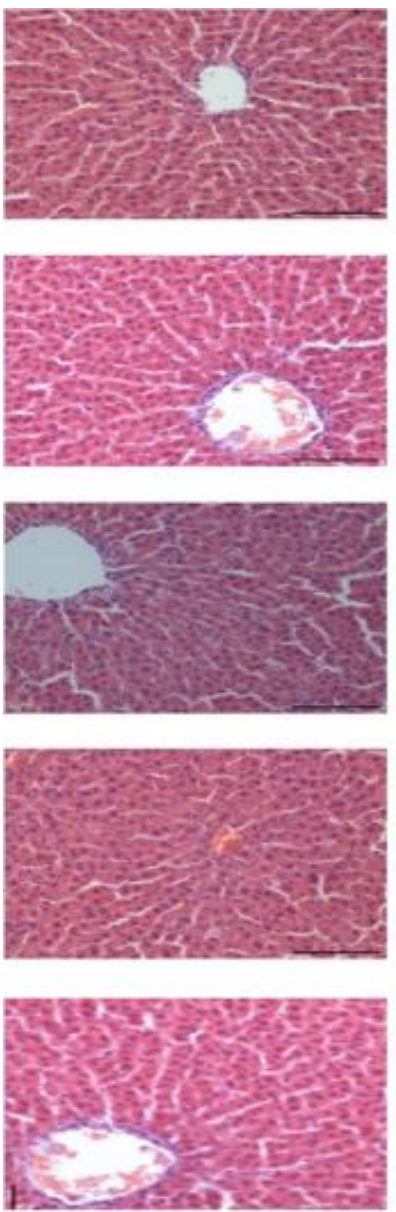

(a)

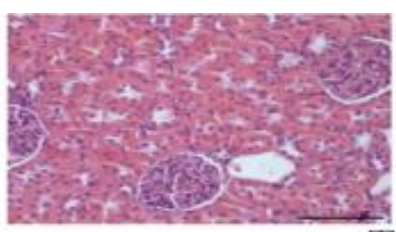

TO

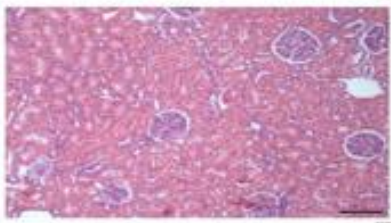

$\mathrm{T}$
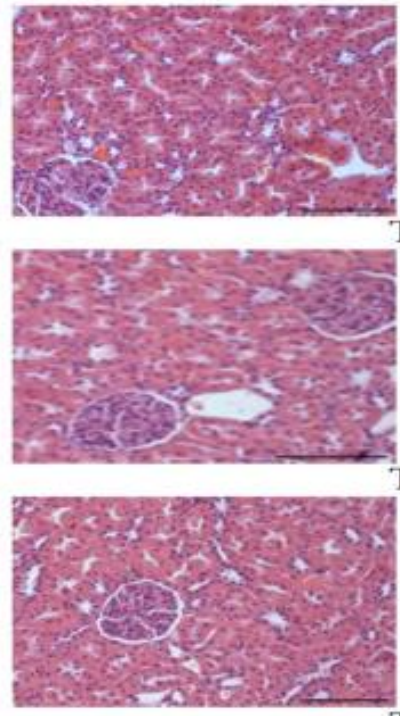

(b) organs analyzed, and neither were injuries, or significant microscopic changes.
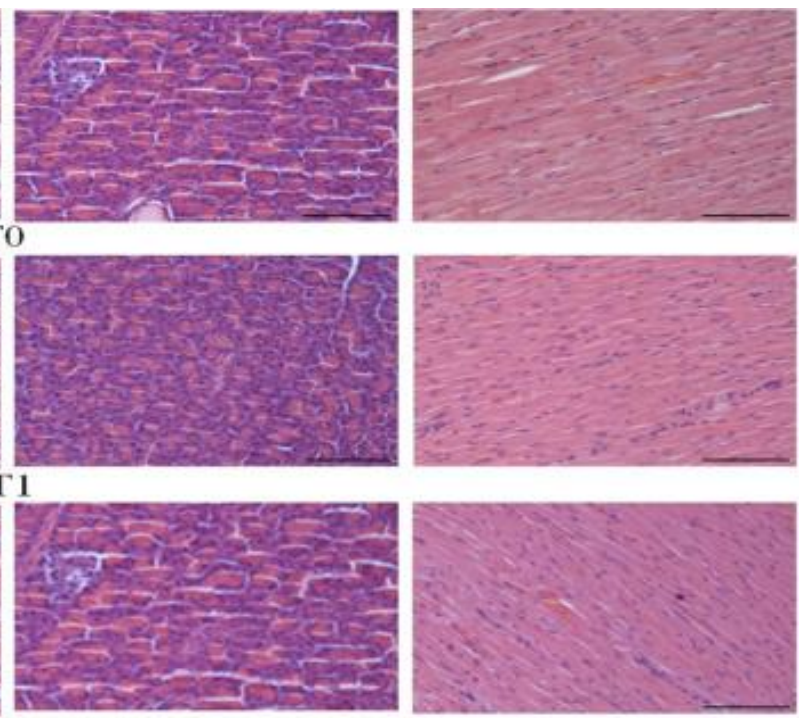

T2
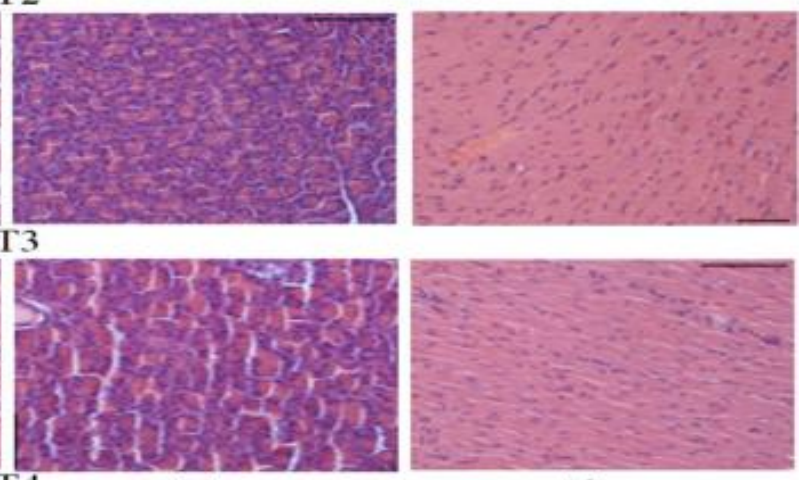

(d)

Figure 4 - Photomicrographs (reading from left to right) of the liver (a), kidneys (b), pancreas (c) and heart (d) of Wistar rats subjected to the treatments: T0 (control) - $1 \mathrm{~mL}$ water/day; $\mathrm{T} 1$ - aqueous extract containing $14 \mathrm{mg}$ phenolic compounds/kg rat/day; T2 - $14 \mathrm{mg}$ quercetina/kg rat/day; T3 - $50 \mathrm{mg}$ flour from Tournefortia paniculata leaves $(\mathrm{FTL}) / \mathrm{kg}$ rat/day and T4 - $100 \mathrm{mg}$ FTL/kg rat/day, for six weeks. 
The possible accumulation of fat in the liver of the animals induced by the hypercaloric diet was not observed in the histology, as well as injuries or destruction of hepatic cells that could release transaminases into the bloodstream, causing an increase in their activity. However, the time period of the experiment might not be sufficient to reveal such damage by the optical microscopy since, for the treatment $\mathrm{T} 2$, there was an increase in the activity of ALT (Table 2) and, for the treated groups, a decrease in the concentration of hepatic fat in relation to the group T0 (control) (Table 1). The results obtained for $T$. paniculata leaves in this study showed the presence of anti-obesity and antioxidant properties, as well as lack of genotoxicity, showing the high pharmaceutical potential of this plant, which could be widely studied as a source of biomolecules or molecular models for the development of new pharmaceutical and/or cosmetic formulations. The results showed the prospects of further studies to determine the doses and investigate other parameters that defined the effectiveness and safety.

\section{ACKNOWLEDGEMENTS}

The authors would like to thank CAPES for the doctoral grant and FAPEMIG for their financial support.

\section{REFERENCES}

Al-Habori M, Al-Aghbari A, Al-Mamary M, Baker M. Toxicological evaluation of Catha edulis leaves: a long term feeding experiment in animals. $J$ Ethnopharmacol. 2002; 83: 209-217.

AOAC. Official methods of analysis of the association of the analytical chemists. 17 ed. Association of Oficcial Anlytical Chemists, Washington, DC. USA. 2005.

Balu M, Sangeetha P, Haripriy AD, Panneerselvam C. Rejuvenation of antioxidant system in central nervous system of aged rats by grape seed extract. Neurosci Lett. 2005; 383: 295-300.

Bertolucci SKV, Pinto JBP, Cardoso M, Gavilanes ML, Santiago EJA, Lameira OA. Micropropagation of Tournefortia paniculata Cham. Rev Bras Plant Med. 2000; 3: 43-49.

Birari RB, Bhutani KK. Pancreatic lipase inhibitors from natural sources: unexplored potential. Drug Discov Today. 2007; 12: 879-889.
Collins AR. The comet assay for DNA damage and repair: principles, applications, and limitations. Mol Biotechnol. 2004; 26: 249-261.

Duarte-Almeida JM, Santos RJ, Genovese MI, Lajolo FM. Evaluation of the antioxidant activity using the $b$-carotene/linoleic acid system and the DPPH scavenging method. Ciênc Tecnol Aliment. 2006; 26: 446-452.

García-Saura MF, Galisteo M, Villar IC, Bermejo A, Zarzuelo A, Vargas F, et al. Effects of chronic quercetina treatment in experimental renovascular hypertension. Mol Cell Biochem. 2005; 270: 147-155.

Ferreira DF. SISVAR: verão 4.6 (build 61) software. Lavras: UFLA, 2003. Available from: htpp://www.dex.ufla.br/danielff/dff02.htm.

Figueroa-Valverde L, Díaz-Cedillo F, Camacho-Luis A. 2009. Efectos inducidos por Ruta graveolens L., Cnidoscolus chayamansa McVaugh y Citrus aurantium L. sobre los niveles de glucosa, colesterol y triacilglicéridos en un modelo de rata diabética. Rev Bras Farmacogn. 2009; 19: 898-907.

Kaneko JJ. Clinical biochemistry of domestic animals. 4 ed. San Diego: Academic, 1989; 932p.

Levin BE, Triscari E, Sullivan AC. Metabolic features of diet-induced obesity without hyperphagia in young rats. Am J Physiol. 1986; 251: 433-440.

Lima AR, Barbosa VC, Santos-Filho PR, Gouvêa CMCP. In vitro evaluation of the antioxidant activity of the hydroalcoholic extract of leaves of bardana. Rev Bras Farmacogn. 2006; 16: 531-536.

Mayer MA, Hocht C, Puyo A, Taiara CA. Recent advances in obesity pharmacotherapy. Curr Clin Pharmacol. 2009; 4: 53-61.

Moraes LD, Sousa OV. Avaliações Qualitativas e Quantitativas da Variação de Metabólitos Secundários em Tournefortia paniculata Cham (Boraginaceae). Rev Bras Biociênc. 2007; 5: 1032 1034.

Motta VM. Bioquímica clínica para o laboratório: princípios e interpretações. 5 ed. Rio de Janeiro: MedBook, 2009; 400p.

Novelli ELB, Diniz YS, Galhardi CM, Ebaid GMX, Rodrigues HG, Mani F, et al. Anthropometrical parameters and markers of obesity in rats. Lab Anim. 2007; 41: 111-119.

Park MY, Lee KS, Sung MK. Effects of dietary mulberry, Korean red ginseng, and banaba on glucose homeostasis in relation to PPAR- $\alpha$, PPAR- $\gamma$, and LPL mRNA expressions. Life Sci. 2005; 77: 3344-3354.

Scalbert A, Johnson IT, Saltmarsh M. Polyphenols: antioxidants and beyond. Am J Clin Nutr. 2005; 81: 215-217.

Simão AA, Corrêa $\mathrm{AD}$, chagas $\mathrm{PMB}$. Inhibition of digestive enzymes by medicinal plant aqueous extracts used to aid the treatment of obesity. $\mathrm{J} \mathrm{Med}$ Plant Res. 2012; 6: 5826-5830. 
Simão AA, Lage FF, Chagas PMB, Fraguas RM, Freire JM, Marques TR, et al. Antioxidants from Medicinal Plants Used in the Treatment of Obesity. Eur J Med Plant. 2013; 3: 429-443.

Singh NP, Mccoy MT, Tice RR, Scheider EL. A simple technique for quantitation of low levels of DNA damage in individual cells. Exp Cell Res. 1988; 175: 184-191.

Souza SP, Pereira LLS, Souza AA, Souza RV, Santos CD. Study of antiobesity activity of methanolic extract of Baccharis trimera (Less.) DC. Rev Bras Farm. 2012; 93: 27-32.

Tucci SA, Boyland EJ, Halford JCG. The role of lipid and carbohydrate digestive enzyme inhibitors in the management of obesity: a review of current and emerging therapeutic agents. Diabetes Metab Syndr Obes. 2010; 3: 125-143.
Urzêda MA, Marcussi S. Pereira LLS, França SC, Pereira PS, Silva S, et al. Evaluation of the Hypoglycemic Properties of Anacardium humile Aqueous Extract. Evid Based Complement Altern Med. 2013; 8 p.

Villareal DT, Apovian CM, Kushner RF, Klein F. Obesity in older adults: technical review and position statement of the American Society for Nutrition and NAASO, The Obesity Society. Am J Clin Nutr. 2005; 13: $1849-1863$.

Yamamoto Y, Oue E. Antihypertensive effect of quercetina in rats fed with a high-fat high-sucrose diet. Biosci Biotechnol Biochem. 2006; 70: 933-939.

Winterbourn CC, Gutterdge JM, Halliwell B. Doxorubicin-dependent lipid peroxidation al low partal pressures of $\mathrm{O}_{2}$. J Free Radic Biol Med. 1985; 1: 43-49. 